\title{
A case of Landau-Kleffner syndrome with SLC26A4-related hearing impairment
}

\author{
Pan Gong, Xianru Jiao and Zhixian Yang* (1)
}

\begin{abstract}
Background: Landau-Kleffner syndrome (LKS) is an acquired aphasia and electroencephalogram (EEG) abnormalities mainly in temporoparietal areas. SLC26A4 mutations can cause hearing loss associated with enlarged vestibular aqueduct (EVA).

Case presentations: We report a case of LKS in a 5-year-old boy with non-syndromic EVA due to homozygous mutations of c.919-2A>G (IVS7-2A>G) in SLC26A4. He had normal language development before 2 years old. At the age of 2.5 years, he was admitted to the hospital due to remarkable language delay, and diagnosed with hearing loss with EVA. The seizures started at 4.4 years of age and EEG recording showed electrical status epilepticus during sleep (ESES) with a posterior-temporal predominance. He received cochlear implantation in the right ear at 4.7 years of age, which improved his hearing and language skills. The nocturnal focal motor seizures recurred at 4.9 years of age. Then a remarkable inability to respond to calls and reduction in spontaneous speech were noticed. He was treated with methylprednisolone at 5 years old, which controlled the seizures, suppressed ESES, and remarkably improved the language ability. The absence of seizures maintained until the last follow-up at 5.3 years of age, with further improvements in EEG recording and language ability.

Conclusions: The co-existence of LKS and hearing loss caused by SLC26A4 mutations increases the difficulty of LKS diagnosis, especially in the presence of hearing loss and impaired language skills. EEG discharges predominantly in temporoparietal areas, the occurrence of ESES, and language improvement after antiepileptic medications are potential indicators for LKS diagnosis.
\end{abstract}

Keywords: SLC26A4, Epilepsy, Landau-Kleffner syndrome, Hearing loss

\section{Background}

Landau-Kleffner syndrome (LKS) is characterized by acquired aphasia, electroencephalogram (EEG) abnormalities mainly in the temporoparietal region and infrequent seizures with good prognosis [1,2]. The onset of aphasia is usually subacute and it has a progressive course with spontaneous fluctuations over time [3]. Although a majority of patients with LKS have an unclear etiology, the genetic predisposition is suggested as an underlying cause for the epilepsy aphasia spectrum [4].

${ }^{*}$ Correspondence: zhixian.yang@163.com

Department of Pediatrics, Peking University First Hospital, No.1,

Beijing 100034, China
Mutations in the SLC26A4 gene, which encodes the anion exchanger pendrin, are the second most common cause for hereditary hearing loss [5]. There are two main types of associated phenotypes: the syndromic form named Pendred syndrome (OMIM \#274600), characterized by goiter, eventually hypothyroidism and cochlear dysplasia plus enlarged vestibular aqueduct (EVA) or EVA alone; and the non-syndromic form characterized by hearing loss with EVA (OMIM \#600791) [5, 6]. Up to now, more than 200 of SLC26A4 mutations have been reported in different ethnic populations. The mutation c.919-2A>G in SLC26A4 gene is confirmed to be the most common form in Chinese [7]. original author(s) and the source, provide a link to the Creative Commons licence, and indicate if changes were made. The images or other third party material in this article are included in the article's Creative Commons licence, unless indicated otherwise in a credit line to the material. If material is not included in the article's Creative Commons licence and your intended use is not permitted by statutory regulation or exceeds the permitted use, you will need to obtain permission directly from the copyright holder. To view a copy of this licence, visit http://creativecommons.org/licenses/by/4.0/. 


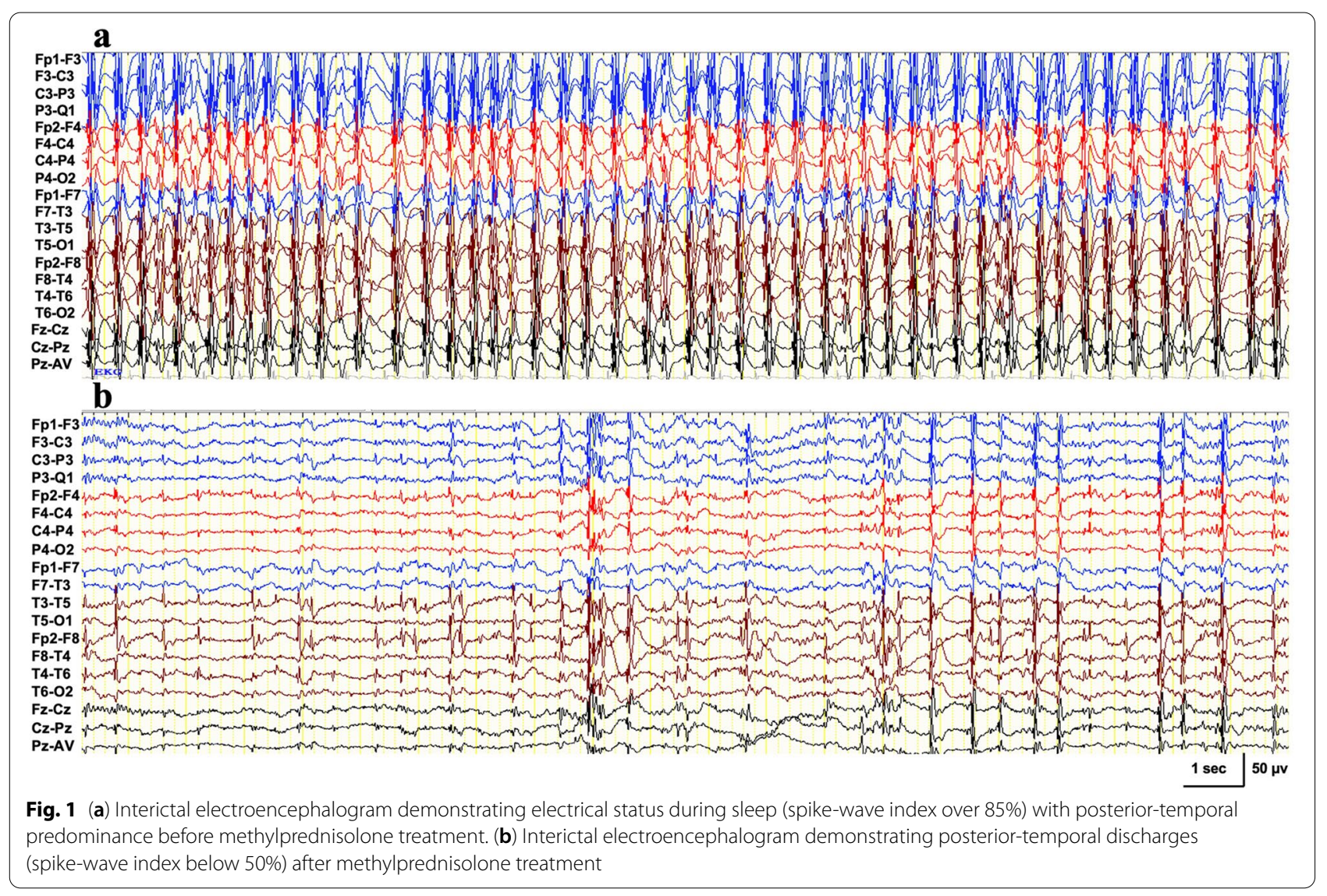

LKS usually starts with the first symptom of verbal auditory agnosia, which is often misdiagnosed as deafness [2]. The co-existence of LKS and hearing loss caused by SLC26A4 mutations may interfere with the diagnosis of LKS. Here, we report a case of LKS in a 5-year-old boy with symptoms of hearing loss and EVA caused by homozygous mutations of c.919-2A>G in the SLC26A4 gene.

\section{Case presentation}

The patient was a 5-year-old boy. He was born to healthy, non-consanguineous parents after a physiological pregnancy. The patient had normal language development but slurred speech before 2 years old. Then he gradually had aphasia. At the age of 2 years and 6 months, he was admitted to the hospital due to remarkable language delay, and was diagnosed as hearing loss with EVA. And he started wearing hearing aids which improved both hearing and speech.

His first seizure occurred at 4.4 years of age, presenting with atypical absence seizures accompanied by clonic seizures for several to hundred times a day. The shortest interval between seizures was $3 \mathrm{~min}$. EEG at seizure onset showed epileptiform discharges in located centrotemporal areas with posterior-temporal predominance and achieved electrical status epilepticus during sleep (ESES) with a spike-wave index (SWI) above 85\% (Fig. 1a). Valproate treatment was initiated, which controlled seizures for 4 months. He received cochlear implantation in the right ear at 4.7 years of age, and wore hearing aids in the contralateral ear, together with speech training. Both hearing and language skills were improved. At 4.8 years of age, nitrazepam treatment was added due to seizure relapse. Then the seizures were reduced but EEG still showed ESES with posterior-temporal predominance. He had recurrent focal motor seizures at sleep for four times in a month starting at 4.9 years of age. Topiramate was added and half a month later, his parents noticed that he was unresponsive to their calls and showed a reduction in spontaneous speech. Then topiramate was withdrawn, but there was no significant improvement in language. Later, levetiracetam was added. On the basis of valproate $(30.9 \mathrm{mg} / \mathrm{kg}$ per day), nitrazepam $(0.4 \mathrm{mg} / \mathrm{kg}$ per day) and levetiracetam (34.5 $\mathrm{mg} / \mathrm{kg}$ per day) treatment, the patient was additionally treated by three courses of methylprednisolone at 5 years old (each course consisted of methylprednisolone administered intravenously at a dose of $10-20 \mathrm{mg} / \mathrm{kg}$ per day 
for 3 days, followed by oral administration at a dose of 1 $\mathrm{mg} / \mathrm{kg}$ per day for 4 days). After three courses, seizures were controlled, EEG showed located posterior-temporal discharges, and the SWI during non-rapid eye movement (NREM) sleep was lower than 50\% (Fig. 1b). And there was a remarkable improvement of language ability. Then prednisolone treatment $(1 \mathrm{mg} / \mathrm{kg}$ per day) was maintained for 2 weeks and was planned to be tapered off within 3 months. Till the last follow-up at 5.3 years of age, no seizures occurred and EEG showed not only a decrease in SWI but also a reduction of the amplitude of epileptiform discharges. And the patient's language ability was further improved.

The patient had no familial history of any neuropsychiatric diseases including epilepsy and febrile seizures. Brain magnetic resonance imaging was normal. Triobased whole-exome sequencing revealed a homozygous mutation of c.919-2A>G (IVS7-2A>G) in the SLC26A4 gene. His parents were both heterozygous carriers of the mutation. No other pathogenic or likely pathogenic mutations were identified, especially in previously reported LKS-related genes.

\section{Discussion}

In this report, we presented a 5-year-old boy with LKS, accompanied by hearing loss with EVA caused by a homozygous mutation of c.919-2A > G in SLC26A4.

The $S L C 26 A 4$ gene is expressed in endolymphatic sac, cochlea and vestibule [8]. Mutations in SLC26A4 are recognized as a cause for autosomal-recessive sensorineural hearing loss [8]. Previous literatures revealed different mutation spectra of SLC26A4 in different ethnic groups. A study in 107 Chinese patients with EVA has indicated that the c.919-2A>G mutation is the most common form of SLC26A4 mutation in Chinese [7]. Consistently, the homozygous c.919-2A>G mutation in SLC26A4 was considered as the pathogenic cause for the hearing loss in our case. The associated phenotypic spectrum with c.919-2A $>$ G mutation ranges from the classical Pendred syndrome (goiter and prelingual profound sensorineural hearing loss) to the non-syndromic recessive hearing loss associated with EVA in the absence of goiter[5]; both are associated with EVA [7]. Here, our case presented with hearing impairment related to EVA but had no sign of goiter, which might be due to the young age. In patients with $S L C 26 A 4$ mutations, there is a great deal of individual variation in the onset and progression of hearing loss and there are fluctuations in the development of hearing loss [9]. A cohort study concluded that patients with SLC26A4 mutation do not necessarily have identifiable hearing loss at birth and that nearly half of newborns can pass the neonatal hearing screening test, although they usually develop severe to profound hearing loss in early childhood [10]. Patients with EVA may have normal hearing in childhood and obtain normal speech and language development with the use of hearing aids [11]. Our case had normal speech and language development before 2 years old. At the age of 2.5 years, he was brought to a doctor due to remarkable language delay noticed by his parents, and then wore hearing aids which improved his language ability. The cohort study mentioned above has reported a significant and rapiddeterioration trajectory of the overall hearing loss in childhood ( $<5$ years), which coincides with the language development period. In patients with biallelic mutations in $S L C 26 A 4$, an average of profound hearing loss ( $>80 \mathrm{~dB}$ $\mathrm{HL}$ ) would develop at the age of 3.2 years, and cochlear implantation is needed [10]. Cochlear implantation are suggested an effective method to provide patients with severe-to-profound hearing loss with hearing, along with excellent speech perception outcomes[11]. Ko et al. suggested that early implantation can provide EVA patients with the opportunity to develop their language skills through a gradual process similar to that experienced by children with normal hearing [12]. During the first year after implantation, patients can steadily develop speech perception and comprehension, and language improvement can be observed almost immediately [13, 14]. In our case, the cochlear was implanted in the right ear at the age of 4.7 years, resulting in a significant improvement of both hearing and language skills within 3 months post-implantation.

LKS, also known as acquired epileptic aphasia, belongs to the spectrum of ESES-related syndromes [1]. LKS generally has an onset at 2-9 years and peaks at 5-7 years [3]. The most crucial clue for the diagnosis of LKS is language degradation, which occurs in children whose language development or language improvement is related to the suppression of the epileptiform discharges [15]. EEG abnormality is also an important component of LKS, where regional spikes, especially those in the fronto-, centro-, or posterior-temporal areas are observed, and $40 \%-50 \%$ of patients might develop ESES [16]. Seizures occur in $70 \%-80 \%$ of LKS patients, which are, however, infrequent and easy to control [1]. Steroids can effectively reduce seizures and suppress ESES [16]. Consistently, here our case showed hallmarks of seizure onset at age of 4.4 , and the seizures were easily controlled, with located posterior-temporal discharges and linguistic deficits. In LKS, the epileptic aphasia is featured by acquired verbal auditory agnosia. The parents noticed that the patient was unresponsive to their calls. The significant speech improvement paralleled ESES suppression after methylprednisolone treatment. In addition to verbal auditory agnosia, no other cognitive or behavioral impairments were observed. Combined with the predominant 
posterior-temporal discharges on EEG, the patient was diagnosed as LKS. The etiology of LKS is unknown. A recent study highlights the possibility LKS have a complex genetic pattern[4]. The underlying mechanisms of the antiepileptic effect of hormones are unclear. It has been suggested that changes in neurochemical transmission may be mediated by glucocorticoids and/or corticosteroid receptors [17]. LKS probably involves disordered distribution of anticonvulsant and proconvulsant neurotransmitters and networks in the speech cortex during development in childhood. In our case, the trio-based whole-exome sequencing identified no pathogenic or likely pathogenic mutations in previously reported LKSrelated genes. Landa et al. have reported three patients with epilepsy, with co-existence of Pendred syndrome caused by biallelic mutations of SLC26A4 without details of these patients [18], and they thought the mutations of $S L C 26 A 4$ may not be the direct cause for epilepsy. In this report, as the roles of mutations in SLC26A4 are unclear in the occurrence of LKS, the c.919-2A>G (IVS7-2A>G) mutation in the SLC26A4 gene seemed more like a coincidence in our case based on the sporadic case reports.

\section{Conclusions}

The co-existence of language regression due to the hearing impairment may interfere with the diagnosis of LKS. Patients with LKS initially show verbal agnosia followed by expression aphasia. Here, the patient had hearing loss that worsened his speech perception prior to the occurrence of LKS, but the speech performance improved progressively after cochlear implantation. Then a remarkable inability to respond to calls and a reduction in spontaneous speech were noticed, with the presence of seizures and posterior-temporal predominant ESES. After seizure control and ESES remission, the expression language is remarkably improved. The location of EEG discharges in temporoparietal areas, the occurrence of ESES and the language improvement with antiepileptic treatment led us to the diagnosis of LKS. Therefore, careful identification is needed to confirm the diagnosis of LKS. Taking into account the relationship between language deterioration and the presence of ESES, early and aggressive therapy is necessary.

\footnotetext{
Abbreviations

LKS: Landau-Kleffner syndrome; EEG: Electroencephalogram; EVA: Enlarged vestibular aqueduct; ESES: Electrical status epilepticus during sleep; SWI: Spike-wave index.
}

\section{Acknowledgements}

Not applicable.

\section{Authors' contributions}

ZXY and PG conceptualized and designed the study. PG and XRJ collected and summarize data. $P G$ drafted the initial manuscript. $P G, X R J$ and $Z X Y$ revised the manuscript. All authors read and approved the final manuscript.

\section{Funding}

This work was supported by grants from the National Natural Science Foundation of China (81771393 and 82171436), Beijing Natural Science Foundation (7202210) and Capital Funds for Health Improvement and Research (2020-2-4077)

\section{Availability of data and materials}

Not applicable.

\section{Declarations}

\section{Ethics approval and consent to participate}

This report was approved by the Ethics Committee of Peking University First Hospital (2016[1135]) and consent was obtained from the patient's parents.

\section{Consent for publication}

The patient's parents gave consent to publish this article.

\section{Competing interests}

The authors declare no conflict of interests.

Received: 3 February 2021 Accepted: 26 November 2021

Published online: 04 January 2022

\section{References}

1. Sánchez Fernández I, Loddenkemper T, Peters JM, Kothare SV. Electrical status epilepticus in sleep: Clinical presentation and pathophysiology. Pediatr Neurol. 2012;47(6):390-410.

2. Stefanatos G. Changing Perspectives on Landau-Kleffner Syndrome. Clin Neuropsychol. 2011;25(6):963-88.

3. Caraballo RH, Cejas N, Chamorro N, Kaltenmeier MC, Fortini S, Soprano AM. Landau-Kleffner syndrome: A study of 29 patients. Seizure. 2014:23(2):98-104.

4. Tsai MH, Vears DF, Turner SJ, Smith RL, Berkovic SF, Sadleir LG, et al. Clinical genetic study of the epilepsy-aphasia spectrum. Epilepsia. 2013;54:280-7.

5. Hilgert N, Smith RJH, Van CG. Forty-six genes causing nonsyndromic hearing impairment: which ones should be analyzed in DNA diagnostics? Mutat Res. 2009;681(2-3):189-96.

6. Wen C, Wang S, Zhao X, Wang X, Wang X, Cheng X, et al. Mutation analysis of the SLC26A4 gene in three Chinese families. Biosci Trends. 2019;13(5):441-7.

7. Wang QJ, Zhao YL, Rao AQ, Guo YF, Yuan H, Zong L, et al. A distinct spectrum of SLC26A4 mutations in patients with enlarged vestibular aqueduct in China. Clin Genet. 2007:72(3):245-54.

8. Kim MA, Kim SH, Ryu N, Ma JH, Kim YR, Jung J, et al. Gene therapy for hereditary hearing loss by SLC26A4 mutations in mice reveals distinct functional roles of pendrin in normal hearing. Theranostics. 2019:9(24):7184-99.

9. Lai CC, Shiao AS. Chronological Changes of Hearing in Pediatric Patients with Large Vestibular Aqueduct Syndrome. Laryngoscope. 2004;114(5):832-8.

10. Mey K, Bille M, Rye Rasmussen SH, Tranebjærg L, Cayé-Thomasen P. The Natural History of Hearing Loss in Pendred Syndrome and Non-Syndromic Enlarged Vestibular Aqueduct. Otol Neurotol. 2019;40(3):e178-85.

11. Wu CM, Sun YS, Liu TC. Long-term speech perception of cochlear implantation in children with large vestibular aqueduct syndrome: how we do it. Clin Otolaryngol. 2008;33(5):472-5.

12. Ko HC, Liu TC, Lee LA, Chao WC, Tsou YT, Ng SH, et al. Timing of surgical intervention with cochlear implant in patients with large vestibular aqueduct syndrome. PLoS One. 2013;8(11):1-9.

13. Clark JL, Roeser RJ. Large vestibular aqueduct syndrome: a case study. J Am Acad Audiol. 2005;16(10):822-8. 
14. Fahy CP, Carney AS, Nikolopoulos TP, Ludman CN, Gibbin KP. Cochlear implantation in children with large vestibular aqueduct syndrome and a review of the syndrome. Int J Pediatr Otorhinolaryngol. 2001;59(3):207-15.

15. Deonna T, Roulet-Perez E. Early-onset acquired epileptic aphasia (LandauKleffner syndrome, LKS) and regressive autistic disorders with epileptic EEG abnormalities: The continuing debate. Brain Dev. 2010;32(9):746-52.

16. Hughes JR. A review of the relationships between Landau-Kleffner syndrome, electrical status epilepticus during sleep, and continuous spike-waves during sleep. Epilepsy Behav. 2011;20(2):247-53.

17. Mehta V, Ferrie CD, Cross JH, Vadlamani G. Corticosteroids including ACTH for childhood epilepsy other than epileptic spasms. Cochrane Database of Sys Rev. 2015;(6):CD005222.

18. Landa P, Differ AM, Rajput K, Jenkins L, Bitner-Glindzicz M. Lack of significant association between mutations of KCNJ10 or FOXI1 and SLC26A4 mutations in pendred syndrome/enlarged vestibular aqueducts. BMC Med Genet. 2013;14:85.

Ready to submit your research? Choose BMC and benefit from:

- fast, convenient online submission

- thorough peer review by experienced researchers in your field

- rapid publication on acceptance

- support for research data, including large and complex data types

- gold Open Access which fosters wider collaboration and increased citations

- maximum visibility for your research: over 100M website views per year

At BMC, research is always in progress.

Learn more biomedcentral.com/submissions 